\title{
Multiple-trait genomic evaluation for milk yield and milk quality traits using genomic and phenotypic data in buffalo in Brazil
}

\author{
R.R. Aspilcueta-Borquis' ${ }^{1}$, F.R. Araujo Neto², D.J.A. Santos ${ }^{3}$, \\ N.A. Hurtado-Lugo ${ }^{3}$, J.A.V. Silva ${ }^{1}$ and H. Tonhati ${ }^{3}$ \\ ${ }^{1}$ Faculdade de Medicina Veterinária e Zootecnia, Universidade Estadual Paulista, \\ Botucatu, SP, Brasil \\ ${ }^{2}$ Instituto Federal de Ciência e Tecnologia Goiano, Rio Verde, GO, Brasil \\ ${ }^{3}$ Faculdade de Ciências Agrárias e Veterinárias, Universidade Estadual Paulista, \\ Jaboticabal, SP, Brasil \\ Corresponding author: $\mathrm{H}$. Tonhati \\ E-mail: tonhati@fcav.unesp.br \\ Genet. Mol. Res. 14 (4): 18009-18017 (2015) \\ Received July 30, 2014 \\ Accepted August 11, 2015 \\ Published December 22, 2015 \\ DOI http://dx.doi.org/10.4238/2015.December.22.27
}

ABSTRACT. The objective of this study was to compare the multi-trait model using pedigree information and a model using genomic information in addition to pedigree information. We used data from 5896 lactations of 2021 buffalo cows, of which 384 were genotyped using the Illumina Infinium ${ }^{\circledast}$ bovine HD BeadChip, considering seven traits related to milk yield (MY305), fat (FY305), protein (PY305), and lactose (LY305), percentages of fat $(\% \mathrm{~F})$ and protein $(\% \mathrm{P})$, and somatic cell score (SCS). We carried out two analyses, one using phenotype and pedigree information (matrix $\mathrm{A}$ ) and the other using the relationship matrix based on pedigree and genomics information (a single step, matrix $\mathrm{H}$ ). The (co)variance components were estimated using multiple-trait analysis by the Bayesian inference method. The model included the fixed effects of contemporary groups (herd-year and calving season), and the age of cow at calving as (co)variables (quadratic and linear effect). The additive genetic, permanent environmental, and residual effects were included as random effects in the model. The estimates of heritability using matrix $A$ were $0.25,0.22,0.26$, 
$0.25,0.37,0.42$, and 0.17 , while using matrix $\mathrm{H}$ the heritability values were $0.25,0.24,0.26,0.26,0.38,0.47$, and 0.18 for MY305, FY305, PY305, LY305, \%F, \%P, and SCS, respectively. The estimates of breeding values in the two analyses were similar for the traits studied, but the accuracies were greater when using matrix $\mathrm{H}$ (higher than $8 \%$ in the traits studied). Therefore, the use of genomic information in the analyses improved the accuracy.

Key words: Accuracy; Genomics; Milk quality

\section{INTRODUCTION}

The traditional methods of genetic assessment rely on the simultaneous use of phenotypic and genealogical records. There have been many recent suggestions to include information contained in high-density panels of single-nucleotide polymorphisms(SNPs) for the purpose of increasing the accuracy of estimating breeding values, and hence to increase the genetic progress of breeding programs. The integration of this information is a challenge, and many methods have been proposed for this purpose, based on estimating the effects of markers or through correction of the relationship between animals (VanRaden, 2008).

With respect to this last approach, understanding the genomic relationships can improve estimation of the proportion of chromosome segments that are shared by individuals, in view of the possibility of identifying genes that are identical by state, shared through common ancestors. Therefore, the genomic relationship matrix, calculated by different methods (VanRaden, 2008; Gianola and Van Kaam, 2008), can be employed to replace the additive relationship matrix, without major changes in the methods currently used, in what is called the genomic best linear unbiased prediction (GBLUP) method. However, in genomic selection models it is not clear how to account for selection (Aguilar et al., 2010; Chen et al., 2011). Furthermore, it must be assumed that the genotyped animals come from an unselected population (Hayes et al., 2009), something that is often not true in practice.

Another limiting factor is that commercial populations contain non-genotyped and genotyped animals (typically fewer of the latter), making it necessary to integrate data from both groups. For this purpose, a new approach for genomic assessments was proposed by Misztal et al. (2009), who suggested a single-step evaluation with complete data on pedigree, phenotypes, and SNPs (GBLUP). This one-step procedure has a unified structure, eliminates some hypotheses and parameters, and offers the opportunity to calculate genomic assessments more precisely than multistep procedures (Legarra et al., 2009). Furthermore, in comparison with other genomic methods, this approach enables the use of multi-trait models.

Since multi-trait analysis is of great importance in any animal improvement program, the objectives of this study were to compare the estimates of the genetic parameters and the accuracy of values using the BLUP and HBLUP methods, in a simultaneous analysis of milk yield and milk quality traits in dairy buffaloes.

\section{MATERIAL AND METHODS}

\section{Data structure}

We used information from 5896 complete lactations by 2021 buffalo cows, daughters of 114 sires, with calving between 1996 and 2010, supplied by the buffalo milk control program of 
the School of Agrarian and Veterinary Sciences of São Paulo State University (UNESP). Of these animals, 384 cows had been genotyped using the Illumina Infinium ${ }^{\circledR}$ bovine HD BeadChip because of the unavailability of a specific chip for buffaloes. We used the following traits: milk yield (MY305), fat yield (FY305), protein yield (PY305) and lactose yield (LY305), truncated at 305 days, along with the average percentages of fat $(\% \mathrm{~F})$ and protein $(\% \mathrm{P})$, and the somatic cell count (SCC) per lactation. Since the data for this last trait were not normally distributed, they were log-transformed (SCS) using the formula SCS $=\left[\log _{2}(C C S / 100,000)\right]+3$, as proposed by Dabdoub and Shook (1984).

We considered control information obtained by the fifth day of production and retained only the lactations with durations longer than 90 days. For contemporary group (CG) formation, we used the following variables: herd, year, and calving season (October-March and AprilSeptember), with restriction of each CG, which had to contain at least four animals. The analysis used the pedigree file with 6,664 animals in the relationship matrix. The general structure of the data is presented in Table 1.

With respect to the high-density panels, approximately 688,593 SNPs were genotyped, of which 26,042 had fixed alleles and 645,971 presented an allele frequency lower than 0.05 , so that it was possible to use 16,580 SNPs in the analyses. The call rate for all samples varied from 54 to $90 \%$ (mean of $85 \%$ ). For comparison, in bovine samples, call rates above $98 \%$ are reported.

Table 1. Summary of the structure and statistical description for yield of milk (MY305), fat (FY305), protein (PY305) and lactose (LY305), percentages of fat (\%F), protein (\%P), and somatic cell count (SCC).

\begin{tabular}{lcccrrr}
\hline Description & MY305(kg) & FY305(kg) & PY305 $(\mathrm{kg})$ & LY305 & \%F & \%P \\
\hline Records & 5896 & 3325 & 3325 & 3325 & 3325 & 3325 \\
Bulls & 114 & 114 & 114 & 114 & 114 & 114 \\
Cows & 2021 & 2021 & 2021 & 2021 & 2021 & 2021 \\
Mean & 1841.18 & 124.58 & 78.99 & 92.99 & 6.79 & 4.28 \\
SD & 629.42 & 38.16 & 23.49 & 28.54 & 1.29 & 0.62 \\
CV (\%) & 35.21 & 31.19 & 28.96 & 30.66 & 18.86 & 14.30 \\
CG & 309 & 174 & 174 & 174 & 174 & 1.34 \\
\hline
\end{tabular}

$\mathrm{SD}=$ standard deviation, $\mathrm{CG}=$ contemporary group, $\mathrm{CV}=$ coefficient of variation.

\section{Estimation of the (co)variance components}

To obtain the (co)variance components, we carried out a multi-trait analysis, in a Bayesian context, with the GIBBS2F90 program (Misztal et al., 2013). This program implements Gibbs sampling and enables the use of genomic relationship matrices. We considered the fixed effects CG, the number of milkings, and cow age at calving (linear and quadratic) as covariables, and the direct genetic, permanent environment and residual effects as random effects. Therefore, in matrix notation, the complete model can be presented as follows:

$$
y=X \beta+Z a+W p+e
$$

where $\beta, a, p$, and, $e$ are, in this order, the fixed, direct genetic, permanent environment, and residual effects; and $X, Z$, and $W$ are, respectively, the incidence matrices referring to the fixed effects, direct genetic random effect and permanent environment effect. We established a uniform distribution for $\beta$ a priori, reflecting vague previous knowledge about this vector; Gaussian distributions for the random effects; and the inverted Wishart distribution for the (co) variance components: 


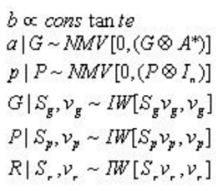

(Equation 2)

where $G, P, R$, and $I_{n}$ are, in this order, the covariance matrices of direct genetic, permanent environment, residual effects, and the identity matrix; $\otimes$ is the Kronecker product operator, in which $S_{g}$ and $v_{g}, S_{p}$ and $v_{p}$, and $S_{r}$ and $v_{r}$ are the a priori values and degrees of freedom for the direct additive, permanent environment, and residual (co)variances, respectively. The matrix $A^{*}$ represents the relationship matrix between the animals, varying according to the method employed (BLUP or HBLUP).

As demonstrated by Legarra et al. (2009) and Aguilar et al. (2010), obtaining the matrix $\mathrm{H}$ through the one-step method can be simple, fast, and accurate. Subsequently, Aguilar et al. (2010) and Christensen and Lund (2010) derived the inverse of the matrix $\mathrm{H}$ :

$$
\mathbf{H}^{-1}=\mathbf{A}^{-1}+\left[\begin{array}{cc}
0 & 0 \\
0 & \mathbf{G}^{-1}-\mathbf{A}_{22}^{-1}
\end{array}\right]
$$

where $\mathrm{G}^{-1}, \mathrm{~A}^{-1}$, and $\mathrm{A}^{-1}{ }_{22}$ are, respectively, the inverse of the genomic matrix, as proposed by VanRaden (2008); the inverse of the traditional relationship matrix, following the rules proposed by Henderson (1978); and the inverse of the traditional relationship matrix considering only the section related to the genotyped animals.

A chain length of a million cycles was established, with a burn-in period of 100,000 cycles and a sampling interval of 100 cycles, which corresponds to 9,000 samples to make inferences. The convergence was verified by graphic inspection, using the $\mathrm{R}$ software, which was also used to obtain descriptive statistics of the posterior distributions of each parameter. The CODA computational package was employed to calculate the number of effective samples (NES) and the posterior highest probability density interval (HPD-95\%), as recommended by Hyndman (1996) as an alternative to the confidence interval, since the latter is not very robust in asymmetric distributions. Samples of the breeding values were also stored to calculate the estimation accuracies, based on the procedure proposed by Gonzáles-Récio et al. (2006), in which the prediction error can be calculated as:

$$
P E V=\frac{\sum_{i=1}^{n s} a_{i}^{2}-\frac{\left(\sum_{i=1}^{n s} a_{i}\right)^{2}}{n s}}{n s}
$$

where $n s$ is the number of samples in a stabilized chain; and a refers to the breeding value of the animal obtained in the $i$-th cycle.

\section{RESULTS AND DISCUSSION}

For all parameters estimated in the two models used in this study, the convergence was verified through inspection of graphs, indicating that the burn-in was sufficient to reach convergence. The effective sample sizes varied from 489 to 4,255 , which are sufficient numbers to obtain the central tendency measures and the highest probability density interval (HPD) for each parameter. The number of samples discarded during the burn-in period and the serial 
correlation obtained between the Markov chains samples are the main aspects of Bayesian analysis (Resende et al., 2001). In general, as the number of parameters to be estimated in the model increases, the burn-in period and serial correlation also increase, leading to a reduction in the effective sample size.

In the comparison between the BLUP and HBLUP, the greatest differences were obtained between the variance components, while the heritability estimates were similar (Tables 2 and 3 ). However, considering the high-density intervals presented, there were no significant differences between the methods for any of the parameters estimated. The similarity between the two methods can primarily be attributed to the number of animals with phenotypic records, which was relatively small, thus causing large errors in the estimates (indicated by the HPD). Another factor was the small number of SNPs obtained (approximately 16,000), which might not have been sufficient to estimate the relationships arising from genes identical in state through the methods employed in this study.

Table 2. Mean, number of effective samples (NES), upper and lower limits of the highest probability density interval (HPD) of the posterior distributions of the variance and heritability components for yield of milk (MY305), fat (FY305), protein (PY305) and lactose (LY305), percentages of fat (\%F) and protein (\%P), and log-transformed somatic cell count (SCC) in buffaloes, using the BLUP model.

\begin{tabular}{|c|c|c|c|c|c|}
\hline \multirow[t]{2}{*}{ Trait } & \multirow[t]{2}{*}{ Parameter } & \multirow[t]{2}{*}{ Mean } & \multirow[t]{2}{*}{ NES } & \multicolumn{2}{|c|}{ HPD } \\
\hline & & & & Lower limit & Upper limit \\
\hline \multirow[t]{4}{*}{ MY305 } & $\sigma_{a}^{2}$ & $46,672.49$ & 1024.48 & $35,883.60$ & $58,364.40$ \\
\hline & $\sigma_{p}^{2}$ & $36,946.85$ & 1267.55 & $29,420.30$ & $44,322.60$ \\
\hline & $\begin{array}{l}p \\
\sigma_{r}^{2} \\
\end{array}$ & $103,861.99$ & $10,000.00$ & $100,030.00$ & $107,450.00$ \\
\hline & $h^{2}$ & 0.25 & 1276.26 & 0.20 & 0.30 \\
\hline \multirow[t]{4}{*}{$\% \mathrm{~F}$} & $\sigma_{a}^{2}$ & 0.24 & 309.30 & 0.17 & 0.31 \\
\hline & $\sigma_{p}^{2}$ & 0.26 & 220.56 & 0.14 & 0.39 \\
\hline & $\begin{array}{l}\sigma_{r}^{2} \\
\sigma_{r}^{2}\end{array}$ & 0.16 & 8051.20 & 0.15 & 0.17 \\
\hline & $h^{2}$ & 0.37 & 219.06 & 0.24 & 0.49 \\
\hline \multirow{4}{*}{$\% \mathrm{P}$} & $\sigma_{a}^{2}$ & 0.03 & 234.54 & 0.02 & 0.04 \\
\hline & $\sigma_{p}^{a}$ & 0.02 & 162.71 & 0.01 & 0.04 \\
\hline & $\sigma_{r}^{2}$ & 0.02 & $10,000.00$ & 0.02 & 0.02 \\
\hline & $h^{2}$ & 0.42 & 155.46 & 0.30 & 0.53 \\
\hline \multirow[t]{4}{*}{ FY305 } & $\sigma_{a}^{2}$ & 276.58 & 975.30 & 188.75 & 363.87 \\
\hline & $\sigma_{p}^{2}$ & 286.06 & 756.04 & 212.33 & 364.54 \\
\hline & $\begin{array}{l}p \\
\sigma_{r}^{2}\end{array}$ & 693.03 & 8940.45 & 655.12 & 729.23 \\
\hline & $h^{2}$ & 0.22 & 905.14 & 0.16 & 0.28 \\
\hline \multirow[t]{4}{*}{ PY305 } & $\sigma_{a}^{2}$ & 96.18 & 567.01 & 73.79 & 118.69 \\
\hline & $\sigma_{\rho}^{2}$ & 80.69 & 265.57 & 62.85 & 99.36 \\
\hline & $\sigma_{r}^{2}$ & 196.06 & $10,000.00$ & 188.05 & 204.03 \\
\hline & $h^{2}$ & 0.26 & 444.84 & 0.20 & 0.31 \\
\hline \multirow{4}{*}{ LY305 } & $\sigma_{a}^{2}$ & 0.42 & 165.93 & 0.25 & 0.62 \\
\hline & $\sigma_{p}^{2}$ & 0.33 & 301.74 & 0.20 & 0.45 \\
\hline & $\sigma_{r}^{p}$ & 0.90 & 5305.79 & 0.82 & 0.96 \\
\hline & $h^{2}$ & 0.25 & 162.02 & 0.16 & 0.35 \\
\hline \multirow[t]{4}{*}{ SCS } & $\sigma_{a}^{2}$ & 115.21 & 645.58 & 87.88 & 142.34 \\
\hline & $\sigma_{p}^{2}$ & 128.63 & 683.24 & 100.78 & 156.15 \\
\hline & $\sigma_{r}^{2}$ & 434.70 & $10,000.00$ & 416.90 & 451.35 \\
\hline & $h^{2}$ & 0.17 & 747.98 & 0.13 & 0.21 \\
\hline
\end{tabular}

$\sigma_{a}^{2}=$ additive genetic variance; $\sigma_{p}^{2}=$ permanent environmental variance; $\sigma_{r}^{2}=$ residual variance; $h^{2}=$ heritability

The heritability estimates were moderate to high in magnitude, except for the SCS values, indicating that for any of the traits studied, genetic gains can be obtained by selecting animals, since some of the differences between individuals are attributed to the average effect of the genes. Estimates with similar magnitudes are described in the literature, both for buffaloes and bovines. 
The heritability value found for MY305 was similar to that reported elsewhere in the literature for bubaline species (Hurtado-Lugo et al., 2006; Tonhati et al., 2008). Rosati and Van Vleck (2002), investigating buffaloes in Italy, reported lower heritability values for constituents of $0.11,0.14,0.14$, and 0.10 for FY, PY, \%F, and \%P, respectively. Values near to these were also reported by Aspilcueta-Borquis et al. (2010), working with animals in the same database: 0.208 , $0.229,0.327$, and 0.39 for FY, PY, \%F, and \%P were observed respectively. With respect to SCS, the values reported in the literature on dairy cattle vary from 0.07 to 0.23 (Da et al., 1992; Weller et al., 1992; Koivula et al., 2005), and in buffaloes, the estimate with the largest magnitude was reported by Aspilcueta-Borquis et al.(2010), with a value of 0.255 .

Table 3. Mean, number of effective samples (NES), lower and upper limits of the highest probability density interval of the posterior distributions of the variance and heritability components for yield of milk (MY305), fat (FY305), protein (PY305) and lactose (LY305), percentages of fat $(\% \mathrm{~F})$ and protein $(\% \mathrm{P})$, and log-transformed somatic cell count (SCS) in buffaloes, using the HBLUP model.

\begin{tabular}{|c|c|c|c|c|c|}
\hline \multirow[t]{2}{*}{ Trait } & \multirow[t]{2}{*}{ Parameter } & \multirow[t]{2}{*}{ Mean } & \multirow[t]{2}{*}{ Samples } & \multicolumn{2}{|c|}{ HPD } \\
\hline & & & & Lower limit & Upper limit \\
\hline \multirow[t]{4}{*}{ MY305 } & $\sigma_{a}^{2}$ & $49,878.863$ & 1888.153 & $37,748.300$ & $62,283.600$ \\
\hline & $\sigma_{p}^{2}$ & $46,510.839$ & 3069.609 & $37,147.500$ & $55,905.000$ \\
\hline & $\sigma_{r}^{p}$ & $104,583.810$ & $10,000.000$ & $100,674.000$ & $108,217.500$ \\
\hline & $h^{2}$ & 0.25 & 2563.032 & 0.193 & 0.303 \\
\hline \multirow[t]{4}{*}{$\% \mathrm{~F}$} & $\sigma^{2}$ & 0.274 & 176.006 & 0.191 & 0.356 \\
\hline & $\sigma_{p}^{2}$ & 0.270 & 182.023 & 0.139 & 0.407 \\
\hline & $\begin{array}{l}p \\
\sigma_{r}^{2}\end{array}$ & 0.179 & 7283.419 & 0.165 & 0.190 \\
\hline & $h^{2}$ & 0.38 & 163.943 & 0.249 & 0.509 \\
\hline \multirow[t]{4}{*}{$\% \mathrm{P}$} & $\sigma_{a}^{2}$ & 0.036 & 226.958 & 0.026 & 0.043 \\
\hline & $\sigma_{p}^{2}$ & 0.025 & 150.334 & 0.012 & 0.038 \\
\hline & $\sigma_{r}^{p}$ & 0.016 & $10,000.000$ & 0.015 & 0.017 \\
\hline & $h^{2}$ & 0.467 & 158.226 & 0.337 & 0.595 \\
\hline \multirow[t]{4}{*}{ FY305 } & $\sigma_{a}^{2}$ & 289.740 & 528.048 & 200.456 & 391.185 \\
\hline & $\sigma_{p}^{a}$ & 301.734 & 500.078 & 218.484 & 378.180 \\
\hline & $\sigma_{r}^{p}$ & 613.974 & 8962.676 & 581.048 & 646.656 \\
\hline & $h^{2}$ & 0.24 & 48.748 & 0.166 & 0.310 \\
\hline \multirow[t]{4}{*}{ PY305 } & $\sigma_{a}^{2}$ & 99.705 & 665.074 & 74.483 & 124.488 \\
\hline & $\sigma_{p}^{2}$ & 90.488 & 571.354 & 70.291 & 111.530 \\
\hline & $\sigma_{r}^{2}$ & 193.232 & $10,000.000$ & 185.431 & 201.990 \\
\hline & $h^{r}$ & 0.26 & 591.181 & 0.198 & 0.317 \\
\hline \multirow[t]{4}{*}{ LY305 } & $\sigma_{a}^{2}$ & 0.389 & 436.535 & 0.227 & 0.570 \\
\hline & $\sigma_{p}^{2}$ & 0.353 & 651.833 & 0.195 & 0.445 \\
\hline & $\sigma_{r}^{p}$ & 0.803 & 7117.009 & 0.737 & 0.865 \\
\hline & $h^{2}$ & 0.26 & 426.717 & 0.158 & 0.354 \\
\hline \multirow[t]{4}{*}{ SCS } & $\sigma_{a}^{2}$ & 121.164 & 735.005 & 90.025 & 150.865 \\
\hline & $\sigma_{0}^{2}$ & 131.948 & 1040.411 & 103.501 & 158.530 \\
\hline & $\begin{array}{l}p \\
\sigma_{r}^{2}\end{array}$ & 421.091 & $10,000.000$ & 404.352 & 437.616 \\
\hline & $h^{2}$ & 0.18 & 711.678 & 0.137 & 0.223 \\
\hline
\end{tabular}

$\sigma_{a}^{2}=$ additive genetic variance; $\sigma_{p}^{2}=$ permanent environmental variance $\sigma_{r}^{2}=$ residual variance; $h^{2}=$ heritability.

Regarding the genetic correlations between the traits studied (Table 4), the BLUP and HBLUP methods presented similar estimates, except for the associations involving SCS, for which the values were antagonistic for the standard method and synergetic when using the genomic information. Through these estimates, regardless of the method used, the indirect genetic gains obtained through selection for milk yield would be minimal for the percentage of each constituent and for the somatic cell count. 
Table 4. Means of the posterior distributions of the genetic correlations for yield of milk (MY305), fat (FY305), protein (PY305) and lactose (LY305), percentages of fat (\%F) and protein (\%P), and log-transformed somatic cell count (SCS) in buffaloes using the BLUP (below the diagonal) and HBLUP model (above the diagonal).

\begin{tabular}{|c|c|c|c|c|c|c|c|}
\hline & MY305 & FY305 & PY305 & LY305 & $\% \mathrm{~F}$ & $\% \mathrm{P}$ & SCS \\
\hline MY305 & - & 0.78 & 0.94 & 0.66 & -0.35 & -0.16 & 0.10 \\
\hline FY305 & 0.73 & - & 0.74 & 0.10 & 0.38 & 0.11 & 0.05 \\
\hline PY305 & 0.93 & 0.64 & - & 0.08 & 0.23 & 0.42 & 0.09 \\
\hline LY305 & 0.68 & 0.12 & 0.12 & - & 0.13 & 0.11 & 0.12 \\
\hline$\% \mathrm{~F}$ & -0.37 & 0.39 & 0.21 & 0.11 & - & 0.33 & 0.18 \\
\hline$\% \mathrm{P}$ & -0.21 & 0.12 & 0.49 & 0.13 & 0.29 & - & 0.17 \\
\hline SCS & -0.10 & -0.11 & -0.12 & -0.15 & -0.08 & -0.10 & - \\
\hline
\end{tabular}

The genetic correlation estimates between MY305 and the constituents (both output and percentage) were near those described in the literature for the species (Tonhati et al., 2000; Rosati and Van Vleck, 2002). Studies of genetic correlation estimates of somatic cells in buffaloes are scarce, but for dairy cattle they indicate a low and positive correlation between the traits for yield and somatic cells (Carlén et al., 2004), like those found using HBLUP in this study.

The mean accuracy estimates of the genetic values predicted for the traits studied in the analysis using HBLUP were greater than those in the analysis employing BLUP (Table 4), providing increments of $8.67,8.52,8.97,11.39,12.74,11.97$, and 12.05\%, respectively, for MY305, FY305, LY305 PY305, \%F, \%P, and SCS. There was also lower spread of the accuracy values (considering the standard deviation), and there was evidence of an increase in accuracy only for the genotyped animals. Regarding the comparison of the breeding value estimate (EBV) between the two methods, the Pearson correlations indicated few changes for the groups of genotyped animals and bulls, with the lowest values found in the comparison of the estimates in the whole population (Table 5). In the sample used, the genotyped animals and bulls presented relatively good accuracies, and the inclusion of this information caused few alterations in the estimation of the breeding values of these animals.

Table 5. Means and standard deviations (SD) of the prediction accuracy of the breeding values and Pearson correlation in the selection of animals classified by the classic breeding value (BLUP) and the breeding value using genomic information (HBLUP), for yield of milk (MY305), fat (FY305), protein (PY305) and lactose (LY305), percentages of fat (\%F) and protein (\%P), and log-transformed somatic cell count (SCS).

\begin{tabular}{|c|c|c|c|c|c|}
\hline \multirow[t]{2}{*}{ Traits } & \multicolumn{2}{|c|}{ Mean accuracy } & \multicolumn{3}{|c|}{ Pearson correlation } \\
\hline & BLUP & HBLUP & Total & Genotyped & Bull \\
\hline MY305 & $0.66 \pm 0.16$ & $0.72 \pm 0.09$ & 0.74 & 0.92 & 0.97 \\
\hline FY305 & $0.58 \pm 0.15$ & $0.63 \pm 0.11$ & 0.68 & 0.87 & 0.96 \\
\hline PY305 & $0.58 \pm 0.16$ & $0.63 \pm 0.11$ & 0.67 & 0.86 & 0.96 \\
\hline LY305 & $0.59 \pm 0.15$ & $0.66 \pm 0.10$ & 0.71 & 0.84 & 0.95 \\
\hline$\% \mathrm{~F}$ & $0.61 \pm 0.14$ & $0.69 \pm 0.09$ & 0.70 & 0.89 & 0.94 \\
\hline$\% \mathrm{P}$ & $0.62 \pm 0.13$ & $0.69 \pm 0.09$ & 0.70 & 0.89 & 0.93 \\
\hline SCS & $0.57 \pm 0.19$ & $0.64 \pm 0.13$ & 0.71 & 0.88 & 0.92 \\
\hline
\end{tabular}

The results presented should be discussed in light of the properties of the HBLUP method. First of all, the HBLUP method considers homogeneous variance for all SNPs, while results for dairy cattle with other methods (BayesA, BayesB, and Bayesian Lasso) demonstrate that this assumption in many cases is wrong, causing lower efficiency of the genome matrix, as verified in simulation studies (Garrick et al., 2009). Considering the database used, some QTLs with greater effect may have occurred. This can diminish the efficiency of the HBLUP method, possibly 
making the control even more difficult when considering the small number of SNPs evaluated. Nevertheless, to enable a multi-trait analysis, alternatives have been developed for the HBLUP., To allow using the heterogeneity of variance of the SNPs in the HBLUP method Wang et al. (2012) proposed an interactive method that, despite the results presented in simulations in the same study, demonstrated questions with respect to the convergence of the process. Nevertheless, this process is still being used in uni-trait form. Other possibilities to increase the accuracy are based on the use of specific genome matrices for each trait, so that only a single-trait analysis is carried out, as occurs in the Bayesian regression methods.

\section{CONCLUSIONS}

The heritability estimates for all the traits under analysis were moderate, allowing them to be used in selection programs, but the genetic correlations between milk yield and percentages of fat and protein, and somatic cell score are not desirable because they can alter the milk quality. In this process, a balance should be sought between increased milk yield and milk quality. The use of genomic information, based on the results presented, lead to better accuracy of the heritability estimates (lower standard deviation) and accuracy of the genetic values, since a better relationship structure was available.

\section{ACKNOWLEDGMENTS}

Research supported by the State of São Paulo Research Foundation (Fapesp, São Paulo, SP, Brazil) and the National Council of Technological and Scientific Development (CNPq, Brasilia, DF, Brazil).

\section{REFERENCES}

Aguilar I, Misztal I, Johnson DL, Legarra A, et al. (2010). A unified approach to utilize phenotypic, full pedigree, and genomic information for genetic evaluation of Holstein final score. J. Dairy Sci. 93: 743-752.

Aspilcueta-Borquis RB, Araujo Neto FR, Baldi F, Bignardi AB, et al. (2010). Genetic parameters for buffalo milk yield and milk quality traits using Bayesian inference. J. Dairy Sci. 93: 2195-2201.

Carlén E, Strandberg E and A Roth (2004). Genetic parameters for clinical mastitis, somatic cell counts and production in the three first lactations of Swedish Holstein cows. J. Dairy Sci. 87: 3062-3070.

Chen CY, Misztal I, Aguilar I, Legarra A, et al. (2011). Effect of different genomic relationship matrices on accuracy and scale. J. Anim. Sci. 89: 2673-2679.

Christensen O and Lund M (2010). Genomic prediction when some animals are not genotyped. Genet. Sel. Evol. $42: 2$.

Da Y, Grossman M, Misztal I and Wiggans GR (1992). Estimation of genetic parameters for somatic cell score in Holsteins. J. Dairy Sci. 75: 2265-2271.

Dabdoub AM and Shook GE (1984). Phenotypic relations among milk yield, somatic count cells, and mastitis. J. Dairy Sci. 67: 163-164.

Garrick DJ, Taylor JF and Fernando RL (2009). Deregressing estimated breeding values and weighting information for genomic regression analyses. Genet. Sel. Evol. 41: 55.

Gianola D and van Kaam JB (2008). Reproducing kernel Hilbert spaces regression methods for genomic assisted prediction of quantitative traits. Genetics 178: 2289-2303.

González-Recio O, Chang YM, Gianola D and Weigel KA (2006). Comparison of models using different censoring scenarios for days open in Spanish Holstein cows. Anim. Sci. 82: 233-239.

Hayes BJ, Vissher PM and Goddard ME (2009). Increased accuracy of artificial selection by using the realized relationship matrix. Genet. Res 91: 47-60.

Henderson CR (1978). Undesirable properties of regressed least squares prediction of breeding values. J. Dairy Sci. 61: 114-120.

Hurtado-Lugo N, Cerón-Muñoz M and Gutierrez-Valencia A (2006). Estimación de parámetros genéticos para la producción de leche en el día del control en búfalos de la Costa Atlántica Colombiana. LRRD. 18. 
Hyndman RJ (1996). Computing and graphing highest density regions. American Stat 50: 120-126.

Koivula M, Mantysaari EA, Negussie E and Serenius T (2005). Genetic and phenotypic relationships among milk yield and somatic cell count before and after clinical mastitis. J. Dairy Sci. 88: 827-833.

Legarra A, Aguilar I and Misztal I (2009). A relationship matrix including full pedigree and genomic information. J. Dairy Sci. 92: 4656-4663.

Misztal I, Legarra A and Aguilar I (2009). Computing procedures for genetic evaluation including phenotypic, full pedigree, and genomic information. J. Dairy Sci. 92: 4648-4655.

Misztal I, Tsuruta S, Aguilar I, Legarra A, et al. (2013). Methods to approximate reliabilities in single-step genomic evaluation. J. Dairy Sci. 96: 647-654.

Resende MDV, Duda LL, Guimarães PRB and Fernandes JSC (2001). Análise de modelos lineares mistos via inferência Bayesiana. Rev. Mat. e Est. 19: 41-70.

Rosati A and Van Vleck LD (2002). Estimation of genetic parameters for milk, fat, protein and mozzarella cheese production in Italian river buffalo population. Livest. Prod. Sci. 74: 185-190.

Tonhati H, Cerón-Muñoz MF, de Oliveira JA, El Faro L, et al. (2008) Test-day milk yield as a selection criterion for dairy buffaloes (Bubalus bubalis Artiodactyla, Bovidae). Genet. Mol. Biol. 31: 674-679.

VanRaden PM (2008). Efficient methods to compute genomic predictions. J. Dairy Sci. 91: 4414-4423.

Wang H, Misztal I, Aguilar I, Legarra A, et al. (2012). Genome-wide association mapping including phenotypes from relatives without genotypes. Genet. Res. 94: 73-83.

Weller JI, Saran A and Zeliger Y (1992). Genetic and environmental relationships among somatic cell count, bacterial infection, and clinical mastitis. J. Dairy Sci. 75: 2532-2540. 